\title{
Certain applications of heteroatom directed ortho-metalation in sulfur heterocycles
}

\author{
Tarun Kanti Pradhan, Sukhen Chandra Ghosh, and Asish De*
}

Department of Organic Chemistry; Indian Association for the Cultivation of Science; Jadavpur; Kolkata - 700 032; India E-mail: ocad@mahendra.iacs.res.in

Dedicated to Professor (Mrs) Asima Chatterjee on the occasion of her $85^{\text {th }}$ birthday (received 05 Dec 03; accepted 16 March 04; published on the web 24 March 04)

\begin{abstract}
Manifold uses of heteroatom directed ortho-metalation which is responsible for its wide application in aromatic and heteroaromatic chemistry include regiocontrolled introduction of substitutents in aromatic or heteroaromatic ring and manipulation of introduced functionalities leading to chain extension and ring annulation. Metalated compounds also undergo a variety of anionic rearrangements providing synthetic strategies to target molecules. In this article work carried out in the authors' laboratory on the application of this methodology in the field of sulfur heterocycles is reviewed.
\end{abstract}

Keywords: Directed metalation, anionic rearrangements, carboannulation, benzo[b]thiophene, semivioxanthin

\section{Contents}

1. Introduction

2. Directed metalation

2.1. Basic principles

2.1.1. Bases used in DoM

2.1.2. Anionic rearrangements associated with O-carbamate DMG

3. Application of directed metalation in the synthesis of sulfur heterocycles

3.1. Synthesis of benzo[b]thiophene using DoM

3.1.1. Synthesis of benzo[b]thiophene from tertiary benzamides

3.1.2. Synthesis of benzo[b]thiophene from tertiary thiophene carboxamide

3.2. Application of directed metalation in functionalization of benzo[ $[b]$ thiophene

3.3. Application of directed metalation in ring annulation 


\subsubsection{Synthesis of sulfur analogues of semivioxanthin}

3.3.2. Annulation of six-membered oxygen sulfur heterocycles

4. Conclusions

\section{Introduction}

The intellectually stimulating chemistry involved in the synthesis, reactivity and rearrangement of heterocyclic compounds apart from their numerous uses is responsible for the unabated interest of organic chemists in heterocyclic chemistry. Our interest over the past two decades was principally focused on many facades of sulfur heterocycles, a large part of which concerned application of heteroatom directed ortho metalation. ${ }^{1}$

\section{Directed metalation}

Regiocontrolled introduction of substituents into an aromatic ring not only involves the challenge of finding proper reaction conditions but also leads to interesting target molecules through chain extension and ring annulation which require skillful manipulation of introduced functionalities. Heteroatom directed ortho metalation, commonly termed "directed metalation" (DoM) has a distinct edge over over other methods, of which classical electrophilic substitution has been most utilised. Not only DoM does away with the harsh reaction conditions associated with the latter but also provides convenient access to 1,2,3- and 1,2,3,4- contiguously substituted aromatic systems, which becomes a daunting task when classical electrophilic substitution reactions are utilised for this purpose.

\subsection{Directed metalation: basic principles}

After emerging from its long hibernation, which lasted for several decades since its discovery by Gilman $^{2}$ and Wittig ${ }^{3}$, DoM took little time to establish itself as one of the most powerful weapons in the armamentarium of the synthetic organic chemist. This resurgence was made possible by the seminal works reported by several groups like those of Snieckus, Beak, Meyer, Narasimhan, Queguiner, and others.

DoM requires, the presence in the aromatic molecule, of a directed metalating group (DMG) which is an inductively withdrawing atom or group that should also contain a lone pair of electrons. In the presence of a strong base, usually alkyl lithium, deprotonation occurs in the position ortho- to the DMG. The ortho- lithiated species is stabilised by coordination and affords exclusively ortho- substituted product upon quenching with an electrophile (Scheme 1). 


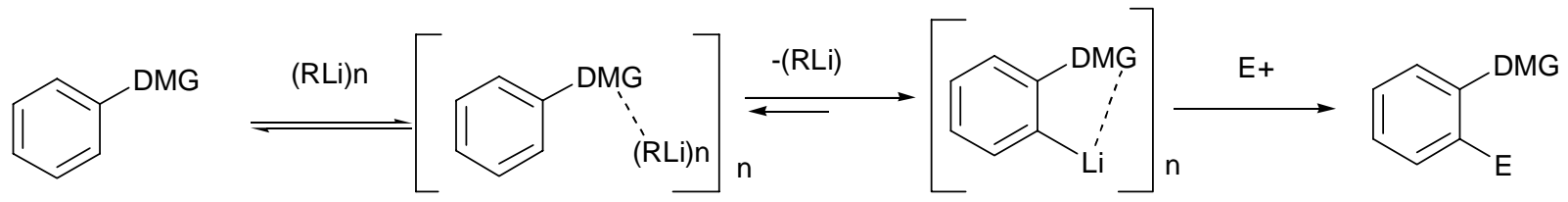

\section{Scheme 1}

Methoxy, the first ever reported $\mathrm{DMG}^{2,3}$ was followed by a large number of other DMGs of varying directing power that were reported ${ }^{1}$ during the course of resurgence of interest in DoM. The extensive use of tertiary amide and $O$-carbamate DMGs is due to their high directing power and the possibility of further manipulation of these functionalities in the lithiated products. Some of these will be illustrated later in this account. Among other moderately directing DMGs which have been frequently used are $\mathrm{OMe}^{2-5}, \mathrm{OMOM}^{6}$ and $\mathrm{CO}_{2} \mathrm{H}^{8}$

\subsubsection{Bases used in DoM}

Alkyl lithium bases used in DoM exist as tetramer-dimer ${ }^{8}$ in donor solvents like tetrahydrofuran (THF) commonly used in directed metalation. It is now recognized that most satisfactory results are obtained when $s$-BuLi is used in THF in the presence of $N, N, N^{\prime}, N^{\prime}$-tetramethyl ethylene diamine (TMEDA). The latter serves to break down the alkyl lithium aggregates with concomitant increase in basicity. An interesting example of chemoselectivity associated with TMEDA has recently been reported. ${ }^{4}$ Owing to its insufficient bulk, $n$-BuLi, although used in several cases, is prone to undergo nucleophilic addition to a tertiary amide DMG. Lithium dialkyl amides have been occasionally used $^{9-13}$ in DoM, particularly when thermodynamic deprotonation was desired. Several interesting uses of the powerful LICKOR base ${ }^{14}$, LTMP ${ }^{15}$ and $\mathrm{t}-\mathrm{BuLi}^{16}$ are on record.

\subsubsection{Anionic rearrangements associated with $\boldsymbol{O}$-carbamate DMG}

When $O$-carbamate is the DMG, the lithiated species can be subjected to a variety of rearrangements. Thus ortho-lithiated $O$-carbamate, upon warming to room temperature, in the absence of an electrophile, can undergo a 1,3-carbamoyl transfer (Scheme 2) via an anionic version of ortho-Fries rearrangement.

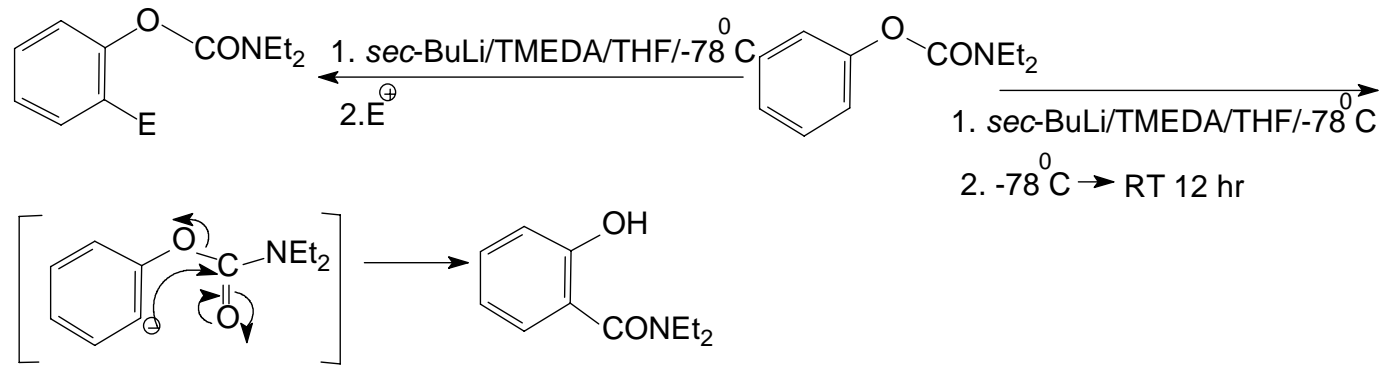

Scheme 2 
A second variety of anionic rearrangement reported by Snieckus ${ }^{17}$ consists of ring-to-ring carbamoyl transfer (Scheme 3).

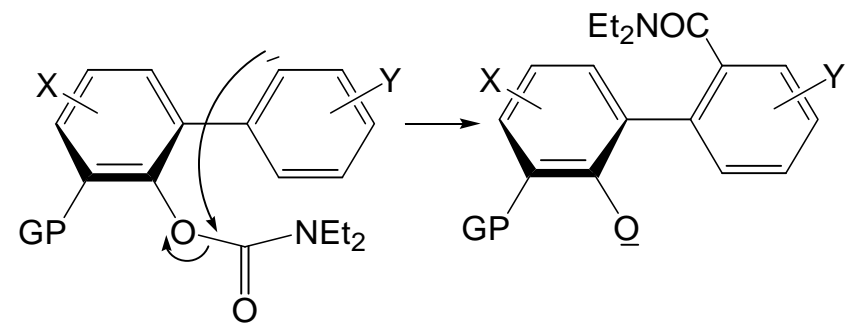

$\mathrm{PG}=$ Protecting Group

\section{Scheme 3}

Anionic homologous ortho-Fries rearrangement, also reported by Snieckus ${ }^{18}$ involves DMG mediated side chain deprotonation of ortho-alkyl $O$-carbamates with LDA, which has been reported to be followed by intramolecular rearrangement (Scheme 4).

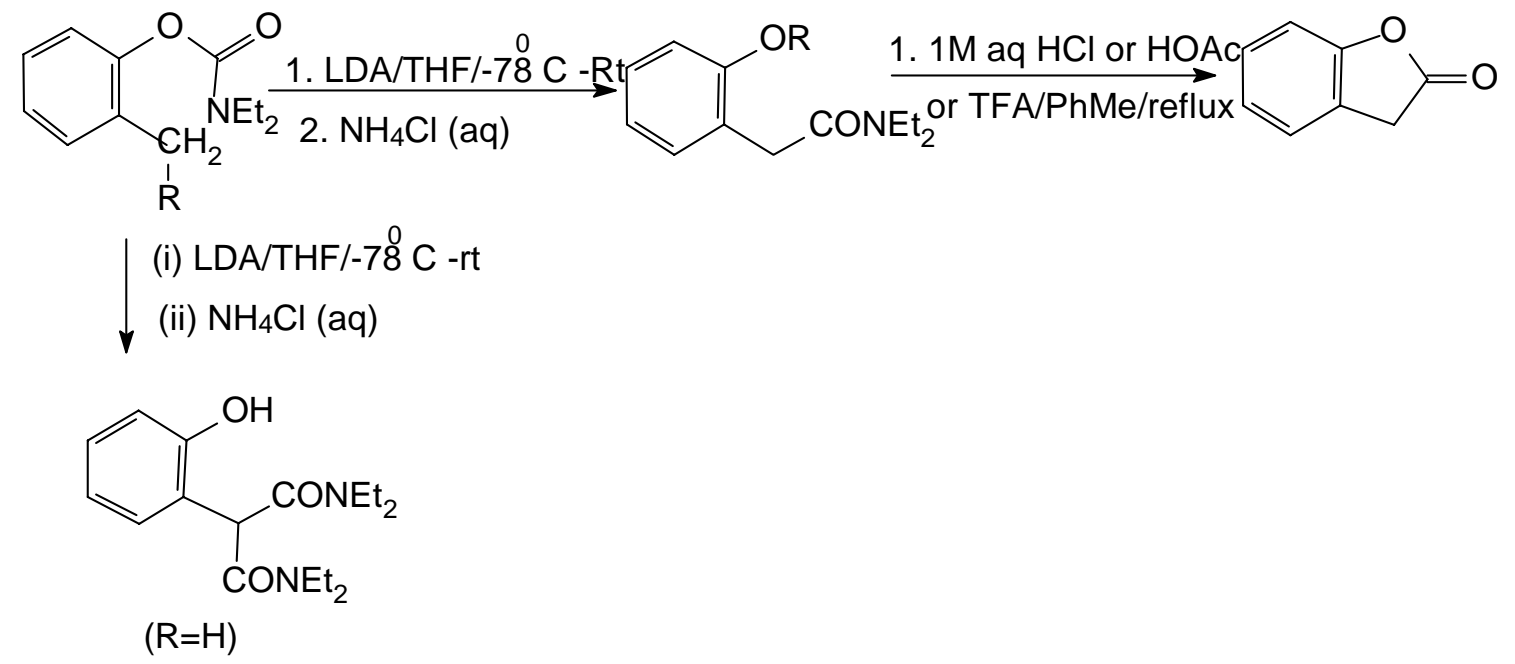

\section{Scheme 4}

The rearranged product may be subjected to acid-induced cyclisation to benzofuran$2(3 H)$ ones, a nucleus present in several natural products.

We have recently reported ${ }^{19}$ a fourth variety of rearrangement (vide infra) which consists of sequential deprotonation of methyl sulfanyl side chain under the influence of ortho-O-carbamate DMG and intramolecular rearrangement. Acid-induced cyclisation of the rearranged product leads to annulation of a six-membered oxygen-sulfur heterocycle on an existing aromatic core (vide infra). 


\section{Application of directed metalation in the synthesis of certain sulfur heterocycles}

In spite of its wide use in the chemistry of aromatic and heteroaromatic compounds, directed metalation has been sparsely used in thiophene and benzothiophene chemistry, although lithiation experiments on both the molecules have long been studied in details. ${ }^{20,21}$ Reported below are several uses of DoM in this area.

\subsection{Synthesis of benzo[b]thiophene using DoM}

Benzo $[b]$ thiophene can be synthesized ${ }^{21}$ either from substituted benzene or from substituted thiophene. We have developed expedient synthesis of benzo[b]thiophene derivatives using DoM methodology via both the routes.

\subsubsection{Synthesis of benzo[b]thiophene from tertiary benzamides}

One of the syntheses developed in our laboratory ${ }^{22,23}$ (Scheme 5) uses as starting material readily available $N, N$-diethylbenzamides carrying different substituents in the benzene ring.

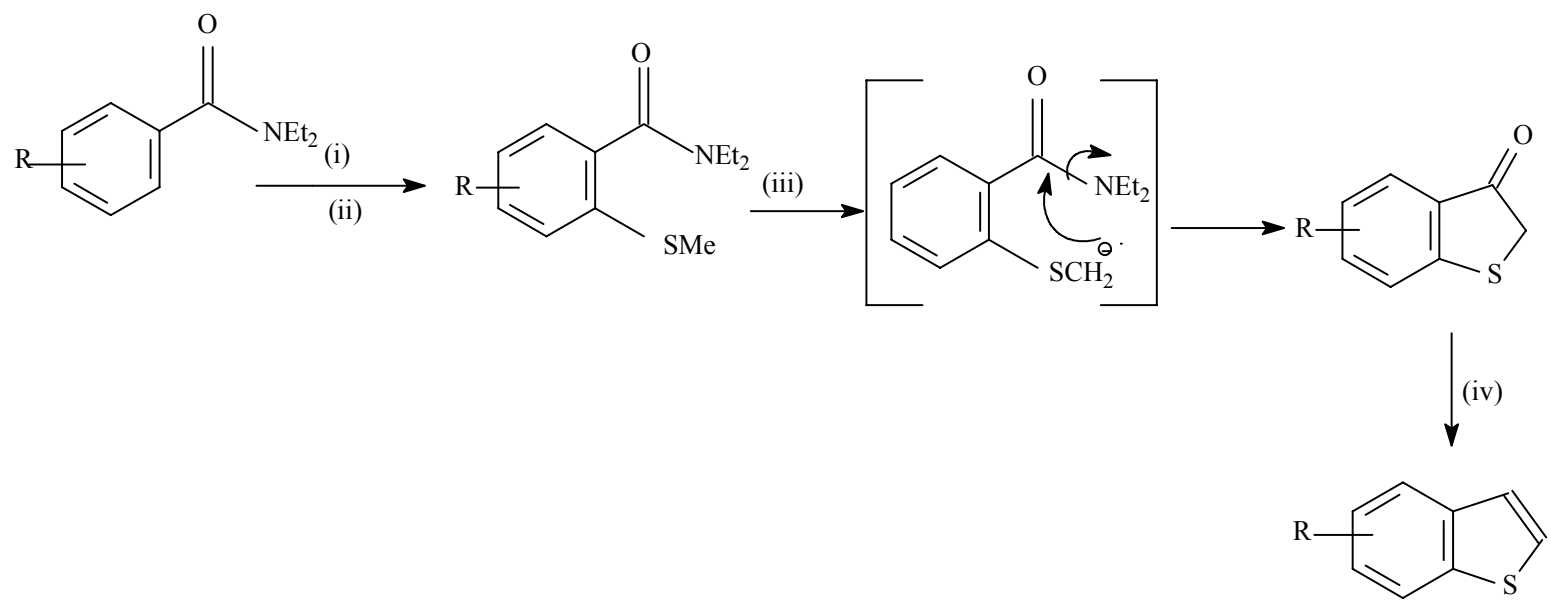

(i) s-BuLi/THF/TMEDA/- $78^{0} \mathrm{C}$; (ii) $\left(\mathrm{SCH}_{3}\right)_{2}$;(iii)LDA/THF/-78 $\mathrm{C}-\mathrm{rt}$; (iv) $\mathrm{NaBH}_{4} / \mathrm{MeOH}$.

\section{Scheme 5}

Methylsulfanyl group was introduced in the position ortho- to the tertiary amide via directed metalation and quenching with dimethyl disulfide. Lateral deprotonation with LDA was followed by instantaneous cyclisation with the tertiary amide acting as the internal electrophile. The resulting thioindoxyls were reduced with sodium borohydride to afford the corresponding benzo[b]thiophene. The method which is a vast improvement over earlier methods of synthesis of these compounds has a wide scope as it leads to a variety of substituted benzo[b]thiophenes (1a-j) (Table 1) and was also extended to the synthesis of a substituted naphthothiophene (1k). 
Table 1. Substituted benzo[b]thiophene

\begin{tabular}{|c|c|c|}
\hline Entry & $\mathrm{R}$ & Yield (\%) \\
\hline $1 \mathrm{a}$ & $\mathrm{H}$ & 67 \\
\hline $1 b$ & 4-SMe & 45 \\
\hline $1 \mathrm{c}$ & 4-OMe & 82 \\
\hline $1 d$ & 5-OMe & 77 \\
\hline $1 \mathrm{e}$ & 6-OMe & 73 \\
\hline $1 f$ & 7-OMe & 71 \\
\hline $1 \mathrm{~g}$ & 6-Me & 92 \\
\hline $1 \mathrm{~h}$ & $4,5-\mathrm{OMe}$ & 73 \\
\hline $1 \mathrm{i}$ & 4, 6-OMe & 85 \\
\hline $1 \mathrm{j}$ & 6, 7-OMe & 78 \\
\hline
\end{tabular}<smiles>[R][R]1ccc2sccc2c1</smiles>

Deprotonation via DoM of one or both the ortho-positions to the tertiary amide function in the parent $N, N$-diethylbenzamide depends on the amount of $s$-BuLi used. Subsequent quenching with dimethyl disulfide affords either $2(\mathrm{R}=\mathrm{H})$ or $2(\mathrm{R}=\mathrm{SMe})$. However formation of $N, N$ diethyl-2-methylsulfunylbenzamide is always accompanied by traces of the 2,6-dimethylsulfanyl derivative and requires careful chromatographic separation.<smiles>OC1CSc2cccc(Cl)c21</smiles>

4<smiles>COc1csc2cccc(Cl)c12</smiles>

Borohydride reduction of the thioindoxyl (3) synthesized from $N, N$-diethyl-2chlorobenzamide resulted in a complex mixture. Although presence of the carbinol 4 in the crude reaction product was evident from ${ }^{1} \mathrm{H}$ NMR and IR data, all attempts of dehydration to obtain 4chlorobenzo $[b]$ thiophene resulted only in formation of an intractable mixture. Methylation of the crude carbinol with methyl iodide in the presence of potassium carbonate afforded 3-methoxy-4chlorobenzo[b]thiophene (5)

\subsubsection{Synthesis of benzo[b]thiophene from tertiary thiophene carboxamide}

We have reported ${ }^{24}$ a novel synthesis of 7-hydroxybenzo[b]thiophene starting from commercially available thiophene-2-carboxylic acid (Scheme 6). 


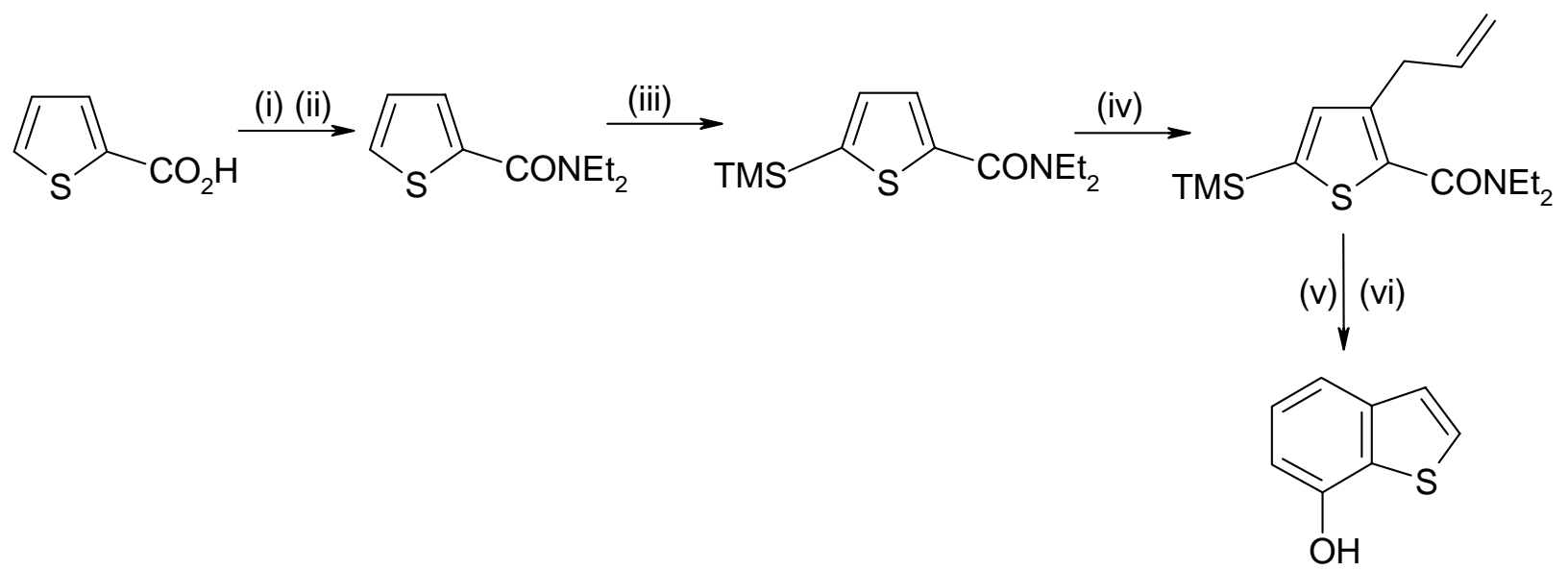

(i) $\mathrm{SOCl}_{2} / \mathrm{Bz} / \mathrm{Reflux}$; (ii) Diethyl amine/Bz; (iii) $s$-BuLi/ TMEDA/THF/TMSCl; (iv) $t$-BuLi/ $\mathrm{THF} / \mathrm{TMEDA} /-78^{0} \mathrm{C}$ to $0^{0} \mathrm{C} / \mathrm{CuBr} . \mathrm{SMe}_{2}$; (v) $\mathrm{LDA}$; (vi) $\mathrm{Bu}_{4} \mathrm{NF}$

\section{Scheme 6}

This synthesis which constitutes a vast improvement over earlier methods of synthesis ${ }^{21}$ of this compound both with respect to the number of steps and overall yield is based on the methodology of anionic carboannulation which exploits the electrophilic character of ortho-allyl tertiary arylamides. ${ }^{25}$ Regiospecific introduction of an allyl function into the 3-position of $N, N$ diethylthiophene-2-carboxamide using DoM requires silyl protection of the 5-position. Exclusive deprotonation is known $^{26}$ to take place in the 5-position of $N, N$-diethyl thiophene-2-carboxamide when one equivalent of $s$-BuLi is used. Use of 2.5 equivalent of $s$-BuLi results in simultaneous deprotonation of the 3- and 5-positions, with the tertiary amide serving as a dianion equivalent. Introduction of an allyl function in the 3-position of the silyl protected amide require transmetalation of the incipient 3-lithio derivative, resulting from DoM, with copper. Cyclisation of $N, N$-diethyl-3-allyl-5-trimethylsilylthiophene-2-carboxamide with LDA and fluoride ion mediated desilylation went on smoothly to afford the target compound.

Anionic carboannulation was utilised by others ${ }^{27}$ to annulate a quinone ring carrying a phenylthio substituent on a thiophene ring.

\subsection{Application of directed metalation in regioselective functionalisation of benzo[b]thiophene}

The advantage which DoM presents over other methods in regioselective functionalisation of aromatic and heteroaromatic molecules has been stated above. DoM mediated regioselective functionalisation of benzo[b]thiophene, most of which was carried out in our laboratory, will be discussed below. 
Japanese workers ${ }^{28}$ successfully metalated 2-methoxybenzo[b]thiophene in the 3-position but failed to recognise it as a DoM reaction. Deprotonation in the 2-position of benzo[b]thiophene, in the presence of a DMG in the 3-position, on the other hand is not strictly a DoM reaction. The acidic nature of the protons in the 2-position of benzo[b]thiophene makes deprotonation facile irrespective of the presence of a neighbouring DMG.

Deprotonation of $N, N$-dimethyl-4,5,6,7-tetrahydrobenzo[b]thiophene-2-carboxamide (6) was accomplished with $t$-BuLi in the $\beta$-position ${ }^{16}$ and the lithio derivative was quenched with a series of representative electrophiles affording the compound 7-10. Compound 7 was further used for annulation. DoM reaction proved to be useful in regiocontrolled functionalisation of a benzene ring in benzo $[b]$ thiophene. Attempts of similar functionalisation with classical electrophilic substitution reactions either results in introduction of the functionality in the 3-position or in the formation of polysubstituted products.

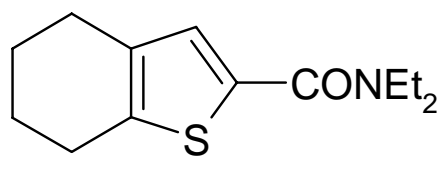

6

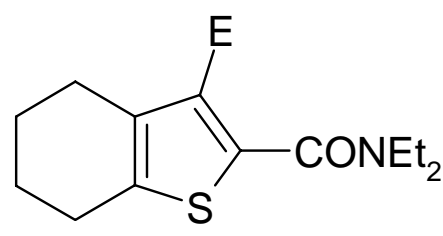

7, $\mathrm{E}=\mathrm{Me}$

8, $\mathrm{E}=\mathrm{CHO}$

9, $\mathrm{E}=$ allyl

10, $\mathrm{E}=\mathrm{CH}(\mathrm{OH}) \mathrm{Ph}$

For DoM reaction in benzo[b]thiophene, carried out with $s$-BuLi (in the presence of TMEDA) and OMe, CONEt 2 and OMOM, were used as DMGs, of which the $O$-carbamate had not surprisingly the most powerful directing ability. Under the DoM conditions, the 2-position was however, deprotonated in preference to the ortho deprotonation by the DMG. Thus, the lithio derivative resulting from deprotonation of both 11 and 12 afforded 13 and 14 upon quenching with methyl iodide used tertiarybutyl dimethyl silyl chloride. The silyl protected compound 14, when subjected to DoM reaction, smoothly deprotonated in the 5-position and afforded 15 in reasonably good yield. ${ }^{29}$ DoM reactions carried out on silyl protected benzo $[b]$ thiophenes with a DMG in the 7-position were comparatively sluggish.<smiles>[R]Oc1cccc2sccc12</smiles>

11, $\mathrm{R}=\mathrm{Me}$

12, $\mathrm{R}=\mathrm{CONEt}_{2}$<smiles>[R]Oc1cccc2sc([R])cc12</smiles><smiles>[R]Oc1c(F)ccc2sc([R16](C)(C)C)cc12</smiles>

13, $\mathrm{R}=\mathrm{Me}, \mathrm{CONEt}_{2}$; $\mathrm{R}^{1}=\mathrm{H}$

14, $\mathrm{R}=\mathrm{Me}, \mathrm{CONEt}_{2}$; $\mathrm{R}^{1}=\mathrm{TBDMS}$ 
Thus compounds 16-18 upon ortho- deprotonation and electrophile quench afforded 19 and 20 in $45 \%$ to $60 \%$ yields. ${ }^{30}$ It was observed ${ }^{29}$ that no silyl protection was necessary when 12 was subjected to anionic ortho-Fries rearrangement; which afforded the rearranged product 21 in $80 \%$ yield and was converted to its methyl ether 22 in $90 \%$ yield upon treatment with methyl iodide in the presence of potassium carbonate.

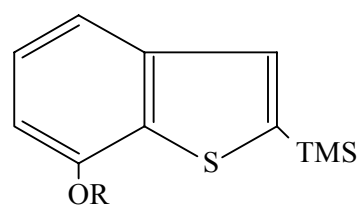

16, $\mathrm{R}=\mathrm{Me}$

17, $\mathrm{R}=\mathrm{CONEt}_{2}$

18, $\mathrm{R}=\mathrm{MOM}$<smiles>CCOC(=O)c1c(F)ccc2cc(S(C)(=O)=O)sc12</smiles>

19

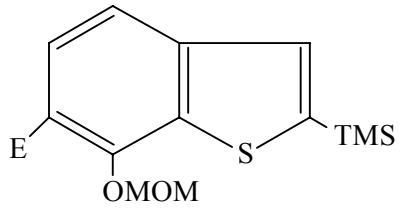

20

(a) $\mathrm{E}=\mathrm{Me}$

(a) $\mathrm{E}=\mathrm{Me}$

(b) $\mathrm{E}=\mathrm{Bu}_{3} \mathrm{Sn}$

(b) $\mathrm{E}=\mathrm{CONEt}_{2}$

(c) $\mathrm{E}=\mathrm{CHO}$

It is surmised that simultaneous deprotonation in the 2- and 5-positions occurs when 12 is treated with $s$-BuLi and the equilibrium between the two deprotonated species slowly shifts towards the 5-lithio derivative in the absence of electrophile quench.

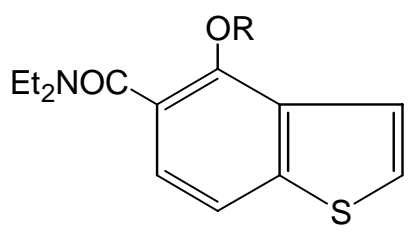

21, $\mathrm{R}=\mathrm{H}$<smiles>CCOC(=O)c1c(C)cc2sc([13C](C)(C)C)cc2c1OC</smiles>

23

22, $\mathrm{R}=\mathrm{Me}$

The anionic ortho-Fries rearrangement generates a new tertiary amide DMG in the 6-position of the benzo[b]thiophene molecule which can be utilised in the synthesis of a 1,2,3-contiguously substituted system after due silyl protection of the 2-position as exemplified by the synthesis of 23 by ortho-deprotonation and quenching with methyl iodide. Compound 23 is a key intermediate in the synthesis of a linearly fused tricyclic system (vide infra).

\subsection{Application of directed metalation in ring annulation leading to polycondensed sulfur heterocycles}

Synthesis of polycondensed systems by carbo- or heteroannulation of introduced functionality is one of the many applications of DoM. ${ }^{1}$ Tertiary amide and $O$-carbamate DMGs are particularly useful in such annulation reactions. This is illustrated by the two expedient synthesis of diversely substituted benzo[b]thiophenes from ortho-methylsulfanyl tertiary benzamides and $N, N$-diethyl3-allyl thiophene-2-carboxamide, described above. Several other examples of such ring 
annulation leading to polycondensed systems incorporating a fused thiophene ring are given below.

\subsubsection{Synthesis of sulfur analogues of semivioxanthin ${ }^{31,32}$}

Semivioxanthin (24) is a linearly fused bioactive naturally occurring naphthopyrone. The sulfur analogues (26-29) were designed by replacing the two benzene rings in turn with thiophene while maintaining the linear naphthopyrone skeleton and allowing variations of the position of the oxygenated functions. The building blocks used in the synthesis of the target molecules are the substituted benzo[b]thiophenes 30-34 of which the first three compounds were accessible from the corresponding thioindoxyls (vide supra) while 5-methoxy benzo[b]thiophene-2carboxylic acid was obtained in several steps from 3-methoxy benzaldehyde following a literature procedure. ${ }^{33}$<smiles>COc1cc(O)c2c(O)c3c(cc2c1)CC(C)OC3=O</smiles>

24<smiles>CC1Cc2cc3ccsc3c(O)c2C(=O)O1</smiles>

25<smiles>COc1c2c(cc3sccc13)CC(C)OC2=O</smiles>

26<smiles>[R]c1cc(OC)c2c3c(sc2c1)C(=O)OC(C)C3</smiles>

27, $\mathrm{R}=\mathrm{H}$<smiles>COc1ccc2sc3c(c2c1)CC(C)OC3=O</smiles>

29

28, $\mathrm{R}=\mathrm{OMe}$

Annulation of a pyrone ring involves a cationic mode of ring closure (35) of ortho-allyl tertiary benzamides in hot mineral acid. Synthesis of the analogues 25 and 26 starts from 4- and 7-N,N-diethyl ortho-carbamoyloxybenzo[b]thiophene (Schemes 7 and 8).

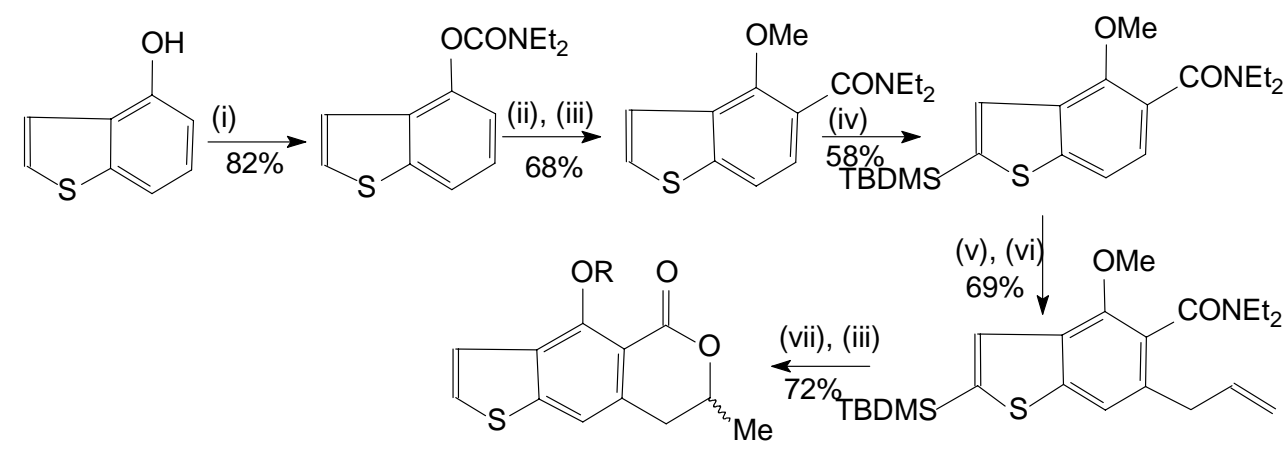

\section{Scheme 7}


Reagents: (i) $\mathrm{NaH} / \mathrm{THF} / \mathrm{ClCONEt}_{2}$, (ii) $s$-BuLi/TMEDA/THF/-78 ${ }^{\circ} \mathrm{C}$, (iii) $\mathrm{K}_{2} \mathrm{CO}_{3} / \mathrm{MeI} /$ Acetone, (iv) $s$-BuLi/TMEDA/THF/-78 ${ }^{0} \mathrm{C} / \mathrm{TBDMSCl}$, (v) $s$-BuLi/THF $/-78^{\circ} \mathrm{C} / \mathrm{CuBr}-\mathrm{Me}_{2} \mathrm{~S}$, (vi) Allyl bromide, (vii) $6 \mathrm{~N} \mathrm{HCl} / \mathrm{reflux} / 55 \mathrm{~h}$. (viii) $\mathrm{K}_{2} \mathrm{CO}_{3} / \mathrm{MeI} /$ Acetone.
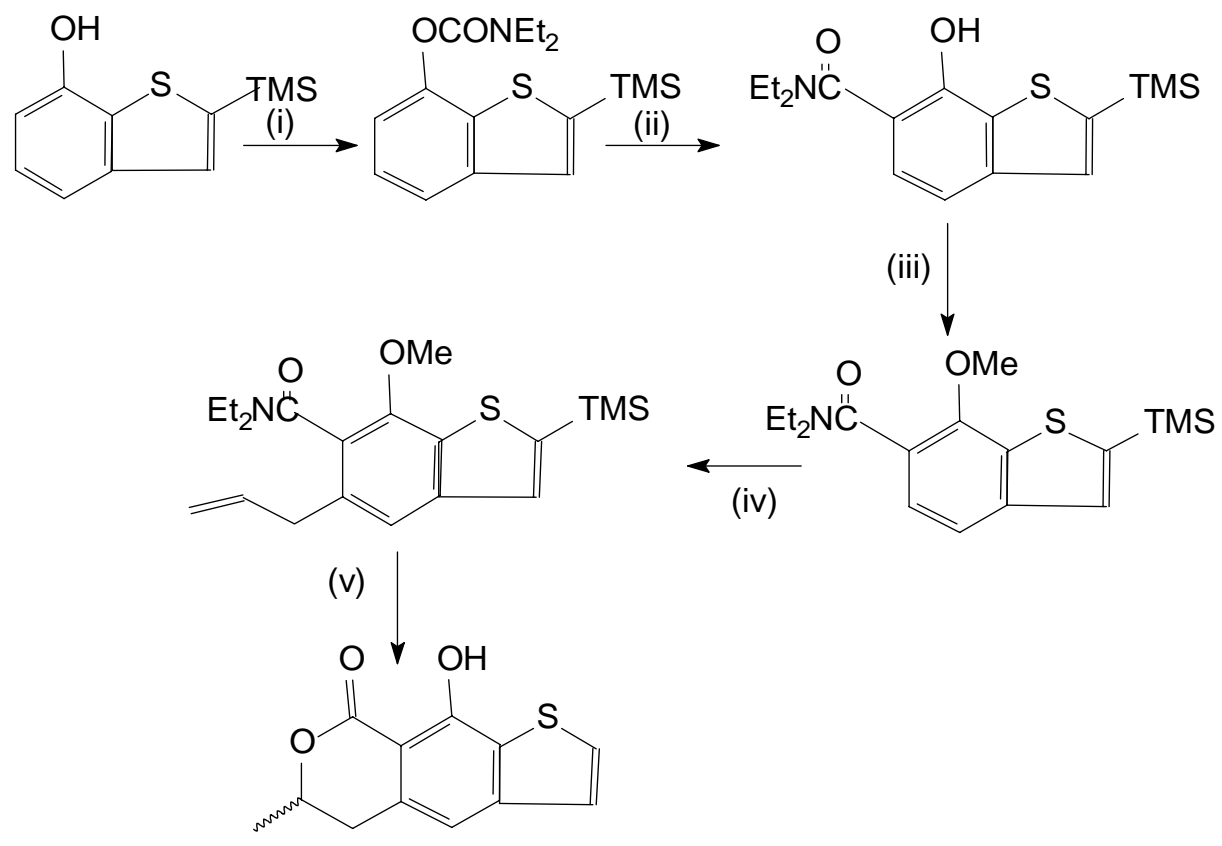

\section{Scheme 8}

Reagents: (i) $\mathrm{NaH} / \mathrm{THF} / \mathrm{ClCONEt} / 2$ rt，(ii) sec- $\mathrm{BuLi}\left(2.5\right.$ equiv)/TMEDA/THF/-78 ${ }^{\circ} \mathrm{C}-\mathrm{rt}$ ，(iii) $\mathrm{K}_{2} \mathrm{CO}_{3}$ (1.2 equiv)/Acetone/MeI，(iv) sec-BuLi (2.5 equiv)/CuBr-Me $2 \mathrm{~S} / \mathrm{Allyl}$ bromide (3 equiv)/THF, (v) $6 \mathrm{~N} \mathrm{HCl} / \mathrm{reflux} / 51 \mathrm{~h}$.<smiles>Oc1cccc2sccc12</smiles>

30<smiles>Oc1cccc2c1SCC2</smiles>

31<smiles>[R]c1cc(OC)c2ccsc2c1</smiles>

$32, \mathrm{R}=\mathrm{H}$<smiles>COc1ccc2sc(C(=O)O)cc2c1</smiles>

34

33, $\mathrm{R}=\mathrm{OMe}$

The synthesis involves sequential anionic ortho-Fries rearrangement, conversion of the sogenerated salicylamide into its methyl ether, introduction of allyl function after silyl protection of the free $\alpha$-position in the thiophene ring and acid induced cyclisation of the ortho-allyl tertiary aryl amide. Desilylation was observed during cyclisation in the case of 25, presumably due to the strong acidic conditions. Syntheses of compounds 27-29 utilised appropriately substituted benzo $[b]$ thiophenes carrying a tertiary amide substituent in the 2-position (Scheme 9-11). 


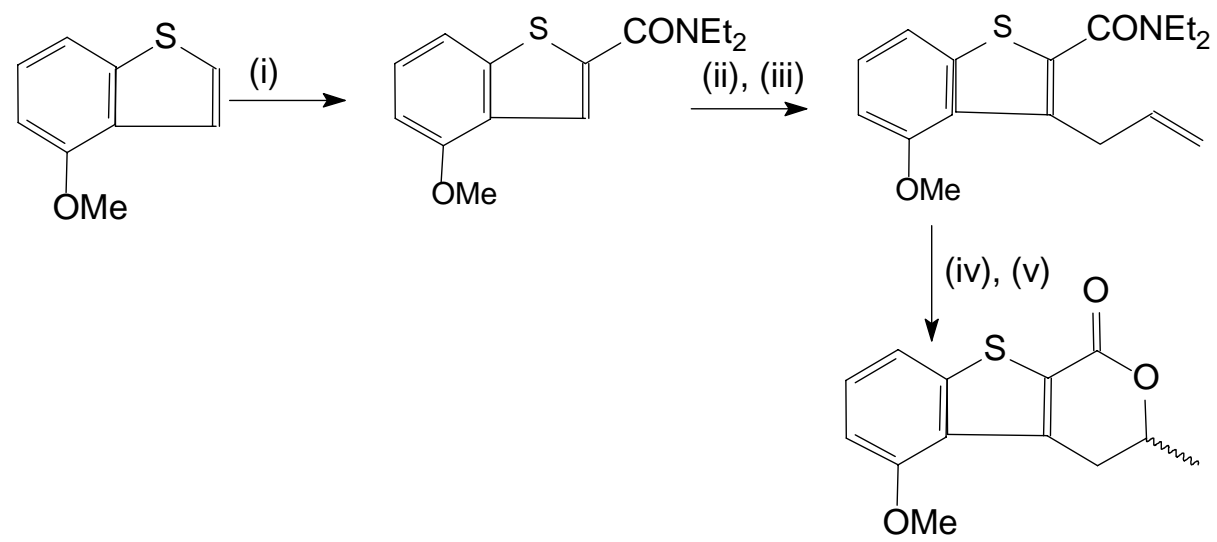

\section{Scheme 9}

Reagents: (i) sec-BuLi/TMEDA/THF/-78 ${ }^{\circ} \mathrm{C} / \mathrm{ClCONEt}_{2}$, (ii) sec-BuLi $/ \mathrm{THF} /-78^{\circ} \mathrm{C} / \mathrm{CuBr}-\mathrm{Me}_{2} \mathrm{~S}$, (iii) Allyl bromide, (iv) $6 \mathrm{~N} \mathrm{HCl} / \mathrm{reflux} / 56-60 \mathrm{~h}$, (v) $\mathrm{K}_{2} \mathrm{CO}_{3} / \mathrm{MeI} /$ Acetone
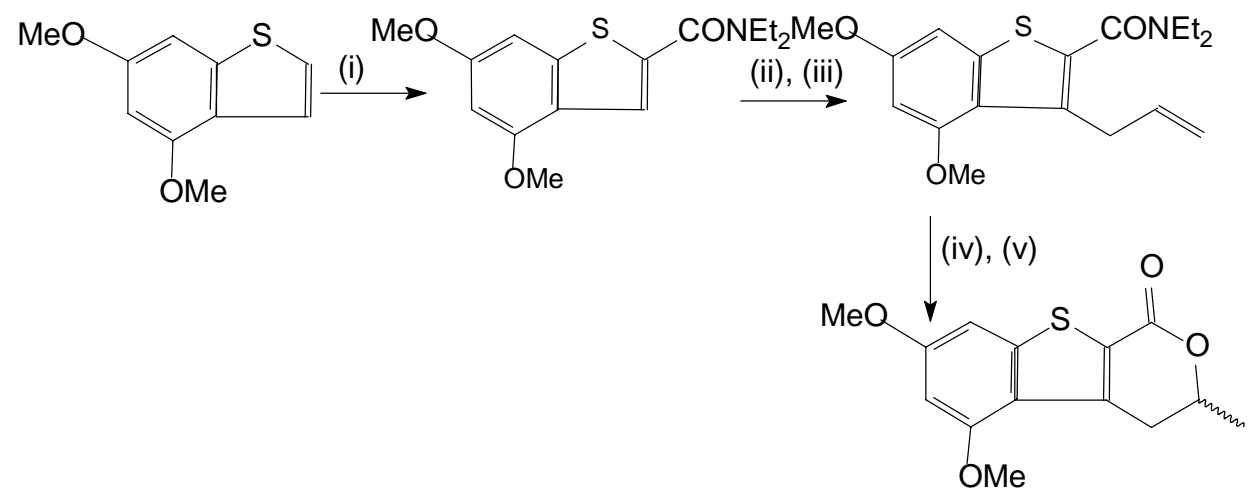

\section{Scheme 10}

Reagents: (i) sec-BuLi/TMEDA/THF/- $78^{\circ} \mathrm{C} / \mathrm{ClCONEt}_{2}$, (ii) sec-BuLi/THF $/-78^{\circ} \mathrm{C} / \mathrm{CuBr}-\mathrm{Me}_{2} \mathrm{~S}$, (iii) Allyl bromide, (iv) $6 \mathrm{~N} \mathrm{HCl} / \mathrm{reflux} / 56-60 \mathrm{~h}$, (v) $\mathrm{K}_{2} \mathrm{CO}_{3} / \mathrm{MeI} /$ Acetone

In all these cases, ortho-allylation using a directed-metalation-transmetalation protocol was followed by acid induced cyclisation leading to the annulation of the pyrone ring. 


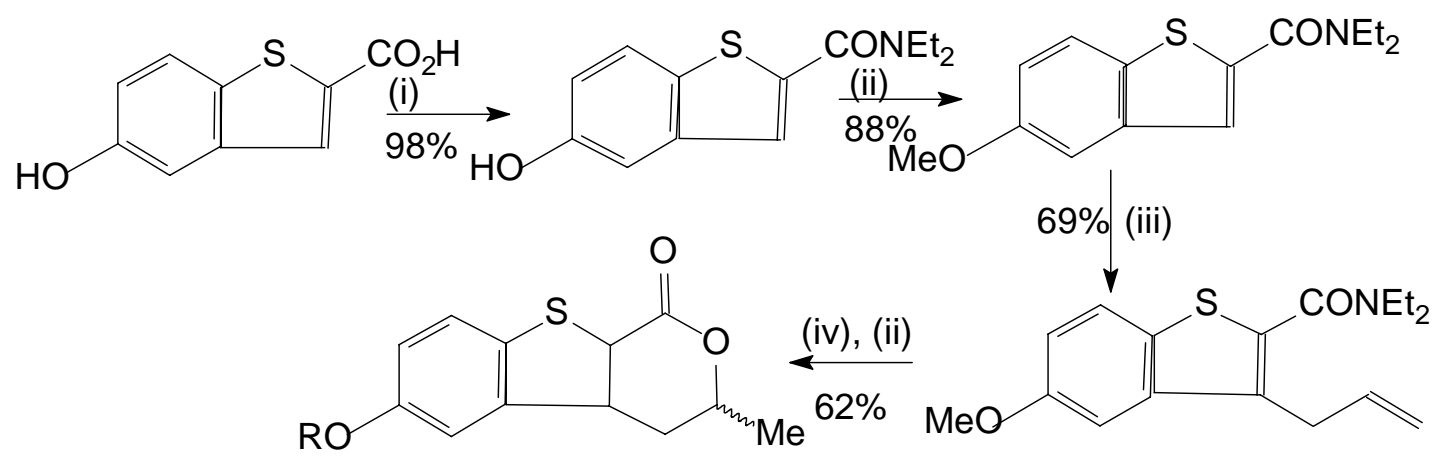

\section{Scheme 11}

Reagents: (i) $\mathrm{SOCl}_{2} /$ Benzene/Diethylamine/reflux, (ii) $\mathrm{K}_{2} \mathrm{CO}_{3} /$ Acetone/MeI, (iii) s-BuLi/THF/$78^{0} \mathrm{C} / \mathrm{CuBr}-\mathrm{Me}_{2} \mathrm{~S} /$ Allyl bromide, (iv) $6 \mathrm{~N} \mathrm{HCl} / \mathrm{reflux} / 39 \mathrm{~h}$.

Linear tricyclic compounds 36 and 37 were synthesized by directed lithiation followed by a chain extension ring annulation protocol.

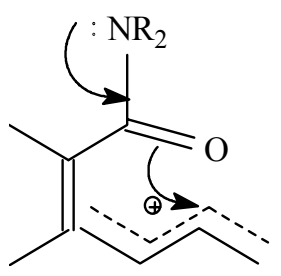

35<smiles>COc1c2c(cc3sccc13)CC(c1ccccc1)OC2=O</smiles>

37<smiles>CC(CC([AlH2])[AlH2])=C(C)C(=O)O</smiles>

38

The precursor to these compound is described above. Side chain deprotonation of a methyl substituent in $\mathrm{N}, \mathrm{N}$-diethyl-O-methylaryl amides, followed by quenching with aryl aldehyde afforded the carbinols of general formula $\mathbf{3 8}$ which were cyclised in hot sodium hydroxide solution to afford the linear tricyclic compounds. ${ }^{16,17}$

\subsubsection{Annulation of six-membered oxygen sulfur heterocycles ${ }^{19}$}

$s$-BuLi mediated deprotonation of the methyl sulfanyl side chain in ortho-methylsulfanyl aryl $O$ carbamates followed by warming to room temperature results in intramolecular anionic rearrangement affording $N, N$-diethyl-2-hydroxyaryl thioacetamides. The latter were cyclised in hot acetic acid leading to annulation of [1,4] oxathiin-2-one to an existing aromatic core (Scheme 12).

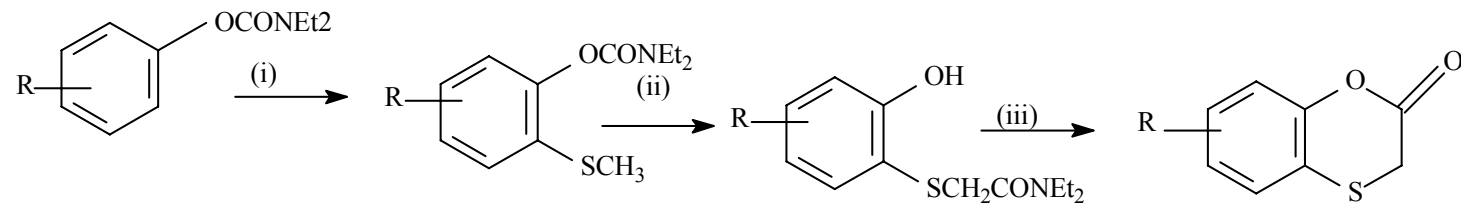

\section{Scheme 12}


(i) $s$-BuLi/ THF/ TMEDA/( $\left.\mathrm{SCH}_{3}\right)_{2} /-78^{0} \mathrm{C}$; (ii) $s$-BuLi/THF/TMEDA/ $-78^{0} \mathrm{C}$ to rt; (iii) Acetic acid/reflux

In a typical experiment, the hydroxy compound $(93 \mathrm{mmol})$ was heated with glacial acetic acid $(7 \mathrm{ml})$ for $18 \mathrm{~h}$ under magnetic stirring. After cooling the reaction mixture was extracted with dichloromethane, the organic layer was washed with water till neutral and dried (anhydrous $\mathrm{Na}_{2} \mathrm{SO}_{4}$ ). Removal of solvent afforded the crude condensed [1,4] oxathiin-2-one which was purified by crystallisation. All the compounds had satisfactory elemental analysis. The carbonyl peak appeared in the IR spectra at $v_{\max } 1760 \mathrm{~cm}^{-1}$ and the signal due to the methylene protons appeared as a two proton singlet at $3.4 \mathrm{ppm}$. Both the rearrangement and the cyclisation steps proceeded with excellent (80-90\% yields). The general applicability of the method was demonstrated by annulating [1,4]oxathiin-2-one ring on substituted benzene and naphthalene cores.

Table 2. Benz[1,4]oxathiin-2-one

\begin{tabular}{lcc}
\hline $\mathrm{R}$ & $\mathrm{Mp}\left({ }^{\mathrm{o}} \mathrm{C}\right)$ & Yield $(\%)$ \\
\hline 8-OMe & 71 & 82 \\
8-Cl & 96 & 81 \\
6-Me, 8-OMe & 121 & 83 \\
\hline
\end{tabular}

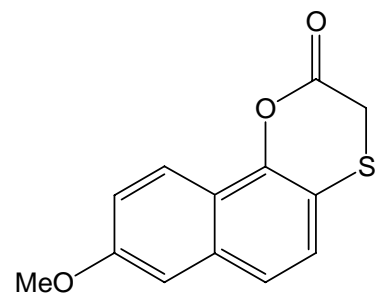

39

It was also observed that when the two ortho-positions of an $O$-carbamate functionality are occupied by methyl and a methylsulfanyl substituent, the rearrangement described above takes place in preference to anionic homologus ortho-Fries rearrangement.

\section{Conclusions}

The importance of DoM reactions and their many ramifications do not need overemphasizing. We have presented above certain applications of this methodology in the synthesis of sulfur heterocycles, where its applications have so far been relatively sparse but as the above account shows it has proved to be extremely useful.

Supporting Information available see page 179

\section{Acknowledgements}

Financial assistance from Royal Society of Chemistry (U.K.) and Council of Scientific and Industrial Research (New Delhi) are gratefully acknowledged. A. D. thanks his collaborators, 
including the co-authors of this paper for their valuable contributions. Their names are mentioned in appropriate places. T.K.P. thanks Council of Scientific \& Industrial Research (New Delhi) for a Senior Research Fellowship.

\section{References and Notes}

1. Snieckus, V. Chem. Rev. 1990, 90, 879.

2. Gilman, H.; Bebb, R. J. Am. Chem. Soc. 1939, 61, 109.

3. Wittig, G.; Fuhrman, F. Chem. Ber. 1940, 73, 1139.

4. Tahara, N.; Fukuda, T.; Iwao, M. Tetrahedron Lett. 2002, 43, 9069.

5. Slocum, D. W.; Moon, R.; Thomson, J.; Coffey, D. S.; Hi, J. D.; Slocum, M. G.; Siegal, A.; Gayton-Garcia, R.; Tetrahedron Lett. 1994, 35, 385.

6. Winkle, M. R.; Ronald, R. C. J. Org. Chem. 1982, 47, 2101.

7. D. Tilly, S. S. Samanta, F. Faigal J. Motier, Tetrahedron Lett. 2002, 43, 8347

8. Wakefield, B. J. The Chemistry of Organolithium Compounds; Pergamon: Oxford, 1974.

9. de Pue J. S.; Collum, D. B. J. Am. Chem. Soc. 1988, 110, 5524.

10. Barr, D.; Clegg, W.; Mulvey, R. E.; Snaith, R.; Wright, D. S. J. Chem. Soc., Chem. Commun. 1987, 716.

11. Renaud, P.; Fox, M. A. J. Am. Chem. Soc. 1988, 110, 5702.

12. Newcomb, M.; Burchill, M. T.; Deeb, T. M. J. Am. Chem. Soc. 1988, 110, 6528.

13. Fraser, R. R.; Mansour, T. S. J. Org. Chem. 1984, 49, 3442.

14. Schlosser, M. Pure and Appl. Chem. 1988, 60, 1627.

15. Mortier J. et al, J. Org. Chem. 2003, 68, 2030.

16. Mukherjee, S.; De, A. J. Chem. Res. 1994, (S) 295 (M) 1735.

17. Wang, W.; Snieckus, V. J. Org. Chem. 1992, 57, 424.

18. Kalinin, A. V.; Jalil Miah, M. A.; Chattopadhay, S.; Tsukazaki, M.; Wicki, M.; Nguyen, T.; Coelho, A. L.; Kerr, M.; Snieckus, V. Synlett 1997, 839.

19. Mukherjee, C.; Kamila, S.; De, A. Synlett 2003, 1474.

20. Gronowitz, S. Adv. Heterocycl. Chem.; Katritzky, A. R.; Boulton, A. J., Eds; Academic Press: New York, 1963; Vol. 1, p 1.

21. Iddon, B.; Scrowston, R. M. Adv. Heterocycl Chem.; Katritzky, A. R.; Boulton, A. J., Eds.; NY, 1970; Vol 11.

22. Mukherjee, C.; De, A. Synlett 2002, 325

23. Mukherjee, C.; Kamila, S.; De, A. Tetrahedron 2003, 59, 476.

24. Samanta, S. S.; Ghosh, S. C.; De, A. J. Chem. Soc. Perkin Trans 1 1997, 2683.

25. Sibi, M. P.; Dankwardt, J. W.; Snieckus, V. J. Org. Chem. 1986, 273.

26. (a) Carpenter, A. J.; Chadwick, D. Tetrahedron Lett. 1985, 26, 1777. (b) Doadt, E. G.; Snieckus, V. Tetrahedron Lett. 1985, 26, 1149.

27. Hay, D. R.; Song, Z.; Snaith, S. G.; Beak, P. J. Am. Chem. Soc. 1988, 110, 8145. 
28. Matsuki, Y.; Adachi, Y. Nippon Kagaku Zasshi 1968, 89, 192; Chem. Abstr. 1968, 69, 67165

29. Mondal, S. S.; Samanta, S. S.; Deb, C.; De, A. J. Chem. Soc. Perkin Trans 1 1998, 2559.

30. General Procedure available on page 179 in the Supporting information

31. Kamila, S.; Mukherjee, C.; De, A. Tetrahedron Lett. 2001, 42, 5955.

32. Kamila, S.; Mukherjee, C.; Mondal, S. S.; De, A. Tetrahedron 2003, 59, 1339.

33. Chakrabarty, P. M.; Chapman, N. B.; Clarke, K. Tetrahedron 1969, 25, 2781. 